\title{
Instituciones, discursos y violencia: la asociación entre locura y peligrosidad ${ }^{1}$
}

\author{
Institutions, discourses and violence: the association between \\ madness and danger
}

Omar Alejandro Bravo

Universidad Icesi, Colombia

omarlakd@gmail.com

\section{Maria Fátima Olivier Sudbrack}

\author{
Universidad de Brasília, Brasil \\ fatsudbr@unb.br
}

Artículo de reflexión recibido el 5/11/09 y aprobado el 31/05/10

\begin{abstract}
Resumen
Las figuras legales denominadas "medidas de seguridad" permiten la reclusión de infractores a la ley, considerados inimputables, en instituciones específicas, conocidas en Brasil, como Manicomios Judiciales. En este artículo se analizan las características de los discursos psiquiátricos y jurídicos que operan en estos casos, su funcionalidad institucional y social y sus consecuencias para los sujetos. Para esto, se toman como referencia las pericias psiquiátricas realizadas a los internos que cumplen estas medidas en el Ala de Tratamiento Psiquiátrico de una prisión de Brasilia, Brasil.
\end{abstract}

Palabras clave: peligrosidad, discursos, locura, instituciones, análisis de discurso.

\begin{abstract}
Individuals who infringe the law but are declared legally un-punishable are, in some cases, committed in specific institutions, known in Brazil as Judiciary Madhouses. This paper analyzes the characteristics of the psychiatric and judiciary discourses that operate in these cases, its consequences for the subjects and their institutional and social functionality. It takes the psychiatric verdicts of individuals housed in the Psychiatric Treatment Area of the Coméia Prison in Brasilia-Brazil and constitutes it as the main information upon which this analysis is based.
\end{abstract}

Key words: Dangerous behavior, Discourses, Madness, Institutions, and Discourse analysis.

1 Esta investigación formó parte de la tesis doctoral en Psicología de Bravo, defendida en el año 2004 en el Instituto de Psicología de la Universidad de Brasilia, bajo la dirección de Sudbrack. 



\section{Introducción}

Como resultado de una serie de procesos históricos, se construyó una percep-

ción social, un imaginario que lleva a juzgar y discriminar lo que es considerado como desviación. Así, según Foucault:

[...] la conciencia moderna tiende a otorgar a la distinción entre lo normal y lo patológico el poder de delimitar lo irregular, lo desviado, lo poco razonable, lo ilícito y también lo criminal. Todo lo que se considera extraño recibe, en virtud de esta conciencia, el estatuto de la exclusión cuando se trata de juzgar y de la inclusión cuando se trata de explicar (Foucault, 1996: 13).

Para el funcionamiento de estos mecanismos, cada sociedad organiza también modelos judiciales y represivos que califican, etiquetan y punen determinadas conductas o personalidades. Lejos de ser un residuo accidental de cada modo de producción y forma histórica, estos dispositivos sirven al propósito de reproducir modelos sociales que, cuanto más injustos en términos de distribución de poder y riqueza, más precisan de su funcionamiento.

Para Zaffaroni y Pierangeli (1999), una sociedad es más autoritaria o democrática según la extensión, complejidad y dirección de sus mecanismos de control social. Este control social excede al sistema penal, involucrando también a la educación, la familia y a todas las instituciones que componen el tejido social, operando directamente por medio de la institucionalización de determinados sujetos (en manicomios, asilos, orfanatos, prisiones, etc.).

A partir de esta realidad, se generan discursos y prácticas que justifican estos dispositivos y ocultan su verdadero sentido. Determinadas ciencias encuentran aquí no solo la explicación de su funcionamiento sino la propia razón de su existencia.

Foucault describe las dimensiones de esta articulación al mostrar cómo:

[...] las prácticas sociales pueden llegar a engendrar dominios de saber que no solamente hacen aparecer nuevos objetos, nuevos conceptos, nuevas técnicas, sino también hacen nacer formas totalmente nuevas de sujetos y de sujetos de conocimiento (Foucault, 1999 : 9).

En la época clásica (siglos XVII y XVIII) la forma y composición interna de las instituciones asilares (que reunían en un conglomerado social difuso a indigentes, leprosos, enfermos, prostitutas y locos) cambia, dando un estatuto particular a los locos y a los infractores de la ley. Los primeros, entendidos como alienados, también son recluidos en instituciones especiales destinadas a su tratamiento y contención. 
La lógica es la misma en los dos períodos citados: colocar el "excedente social" del sistema dentro de una red institucional que aísle a sus integrantes y los rotule, de tal forma que aparezcan como responsables por su situación. La flexibilidad de estas redes institucionales y su carácter discursivo y práctico fluctúa fundamentalmente en función de la cantidad de excluidos que el sistema provoca.

El Estado actual abandonó paulatinamente la función de garantizar la solidaridad social, incluyendo aquí a la salud pública y la asistencia social, que pasan a cumplir apenas funciones paliativas y de contención de la exclusión social. Esta situación de exclusión se expresa en el aumento de la violencia y de las patologías físicas y psíquicas, así como en el empobrecimiento general de los lazos de solidaridad y resistencia.

Esta realidad genera también un aumento en los mecanismos institucionales de contención y estigmatización de estos sectores. De alguna forma, con el aumento brutal de la población carcelaria registrado en los últimos años, se repiten las grandes internaciones descritas por Foucault (1991).

En este sentido, los sistemas penales:

[...] seleccionan un grupo de personas de los sectores más humildes y marginalizados, los criminaliza y muestra al resto de los sectores marginalizados como límites de su espacio social. Al mismo tiempo, también parece que los sectores, que en la estructura de poder tienen la decisión general de determinar el sentido de criminalización, tienen también el poder de substraerse a la misma (Zaffaroni, et al., 1999: 75).

El Art. 26 del Código Penal brasileño permite anular la pena de los sujetos considerados legalmente inimputables y sustituirla legalmente por las denominadas medidas de seguridad, con indicación de reclusión, tratamiento y acompańamiento especializados.

Según este artículo:

Está exento de pena el agente que, por enfermedad mental o desarrollo mental incompleto o retardado era, al momento de la acción u omisión, completamente incapaz de entender el carácter ilícito del acto o de determinarse de acuerdo con ese entendimiento (Brasil, Código Penal, Art. 26).

Sobre el diagnóstico de inimputabilidad penal se construye buena parte de la relación histórica entre el Derecho Penal y la Psiquiatría. Este vínculo comienza desde el momento en que ésta última define su objeto de interés e intervención. Para Foucault (2001), esta definición de objeto proviene de una exigencia de la propia justicia de comienzos de la época moderna que, a partir de la reforma 
propuesta por Beccaria (2000) en la segunda mitad del siglo XVIII y, fundamentalmente en función de la nueva organización social en formación, precisa explicar y encuadrar las conductas de los sujetos en relación a las infracciones a la ley.

Antes de Beccaria, esta discriminación no era necesaria: el delito era considerado una ofensa al soberano y debía ser castigado por una cuestión elemental de reparación que estaba más allá del sujeto infractor y sus motivaciones para constituirse en una demostración de poder dirigida al conjunto de la sociedad.

La seguridad referida en esas medidas es la del cuerpo social, de la población, que debe ser preservada de la convivencia con estos sujetos supuestamente irresponsables de sus actos y peligrosos para los otros. La primera definición de los grupos humanos a ser encuadrados en esta caracterización muestra su espíritu: los anarquistas y los locos se constituyen en objetos privilegiados de intervención.

Para Cohen:

[...] la medida de seguridad, en cuanto providencia preventiva, tiene lugar después del crimen, pero no en razón del mismo, ya que no se puede atribuir culpa al deficiente mental infractor de la ley, y su pretensión es impedir un nuevo peligro social (Cohen, 1996 : 77).

Este encuadre institucional se inserta en un sistema más amplio de prohibiciones y exclusiones que cada sociedad organiza y que no necesariamente está comprendido en ese espacio organizacional. Según Foucault, este sistema:

[...] no coincide realmente con lo ilegal o lo criminal, ni con lo revolucionario, ni con lo monstruoso o anormal, ni tampoco con el conjunto compuesto por la suma de todas esas formas de desviación, sino que cada uno de esos términos lo designa al menos tangencialmente y, en ocasiones, permite reflejar en parte ese sistema que es, para todas las desviaciones y para conferirles sentido, su condición misma de posibilidad y de aparición histórica (Foucault, 1996 : 13).

El análisis del funcionamiento de estos dispositivos institucionales coloca en debate aspectos éticos de la práctica del profesional de la salud mental, quien debe asumir, frente a estos mecanismos, una definición política de las características de su trabajo y un compromiso con el esclarecimiento de las causas reales de la existencia de los mismos.

En este sentido, Aquino destaca que:

"[...] la complejidad de la locura se mezcla en el contexto jurídicopenal con la cuestión de la criminalidad, de la violencia, de la falta de ciudadanía y de la problemática prisional en Brasil. Cuestiones sociales, éticas, y clínicas atraviesan nuestra práctica” (Aquino, 2008: 136). 


\section{La construcción y tratamiento del denominado "loco peligroso"}

Los sujetos encuadrados en el régimen de medida de seguridad, en el Distrito Federal de Brasil ocupan un ala particular de la Cárcel de Comeia, localizada en la ciudad satélite de Gama, denominada Ala de Tratamiento Psiquiátrico (ATP). Aquí se encuentran cerca de 80 hombres (Aquino, 2008); la única mujer que cumple medida de seguridad está en el ala femenina junto a las otras detenidas. La precariedad de la red de salud mental del Distrito Federal dificulta la posibilidad de otras formas de tratamiento.

A partir de la lectura y análisis de los procesos y, en particular, de los laudos psiquiátricos que integran esos cuerpos jurídicos, se colocaron como objeto de esta investigación a los discursos que intervienen en el establecimiento de la inimputabilidad penal de determinadas sujetos infractores a la ley, considerando en particular la forma como esos mecanismos operan en el ámbito particular del Distrito Federal brasileńo y en relación a los asegurados que cumplen su medida en el ala de tratamiento psiquiátrico de la prisión de Comeia. A partir del análisis de este material se hizo una comparación con los discursos presentes en los laudos realizados entre los años 1939 y 1959 en el manicomio Judicial Héctor Carrilho de Rio de Janeiro, primera institución de este tipo en Brasil, con el propósito de mostrar la unidad discursiva de este conjunto de textos, y su pertenencia a una formación discursiva común. De esta manera se colocó en el centro del análisis el funcionamiento del sistema penal y sus relaciones con las prácticas, saberes y discursos que los atraviesan, entre ellos el de la psiquiatría, que ocupa un lugar fundamental en ese proceso.

En un estudio reciente, desde una perspectiva psicoanalítica que enfoca aspectos de la inscripción de la ley simbólica en la subjetividad, esta discusión fue retomada en la disertación de maestría "De la ley a las leyes: reflexiones teórico - clínicas sobre los inimputables" (Aquino, 2008). La autora considera que la medida de seguridad es una medida de defensa social, partiendo de la atribución de peligrosidad realizada a los portadores de algún trastorno mental. Asimismo, intenta encontrar las posibilidades para una clínica en este contexto, refiriéndose a lo que considera como una fase organizadora/paterna de la justicia-amparo y responsabilización- propiciando la reinserción social del "loco infractor". Se relaciona la medida de seguridad y la responsabilización, presentando como especificidad exactamente esta oposición inimputabilidad vs. responsabilidad. Al ser responsabilizado, el sujeto es considerado en su subjetividad sino, también, en su condición de ciudadano sujeto de derechos. 


\section{Algunas cuestiones teóricas y metodológicas que guiaron esta investigación}

Foucault, quien analizó la construcción histórica del vínculo entre psiquiatría y derecho destacando la funcionalidad social de esa relación, opera como una referencia teórica importante para este trabajo. Según el autor, existe una relación directa entre las formas en que los mecanismos jurídicos, los procesos penales y los propios procesos sociales fueron adoptando a lo largo de la historia y los criterios de determinación de verdad que cada sociedad desarrolló.

Para Foucault:

Sólo puede haber ciertos tipos de sujetos de conocimiento, ciertas órdenes de verdad, ciertos dominios de saber a partir de condiciones políticas que son el suelo en el que se forman el sujeto, los dominios de saber y las relaciones con la verdad (Foucault, 1999 : 27).

En este trabajo se toma distancia de algunos temas relacionados con la concepción foucaultiana de poder, reivindicando el carácter vertical en el que el poder se construye y ejerce, y que solo posteriormente se expresa de manera particular en cada actor social. Por lo tanto, las clases sometidas ( $y$ al hablar de clases se introduce también una lectura estructural del fenómeno) construyen alternativas desde lo colectivo que suponen que la disputa por el poder permite su transformación.

El análisis de discurso, herramienta metodológica usada en esta investigación, permite comprender las dimensiones sociales, ideológicas y políticas presentes en un discurso que, a su vez integra formaciones discursivas más amplias unidas por su pertenencia a un espacio ideológico o a un fin común, (Foucault, 1973). El discurso es considerado aquí como una institución producto y productora de la realidad social a la que pertenece. De esta manera, un análisis de discurso debe insertarse en una lectura institucional más amplia que contemple fundamentalmente las relaciones sociales que lo producen y lo tornan hegemónico.

El discurso para Foucault (1973), puede ser definido como un conjunto de enunciados que encuentran sus principios de regularidad en una misma formación discursiva. El enunciado es la unidad elemental, básica que forma un discurso y se diferencia de la proposición como unidad constitutiva de la lógica, y de la frase como unidad lingüística de la enunciación (Bravo, 2000). Los discursos se enmarcan en determinadas formaciones discursivas, definidas como:

[...] un conjunto de reglas anónimas, históricas, siempre determinadas en tiempo y espacio, que definirán en una época y para una área social, económica, geográfica o lingüística, las condiciones de ejercicio de la función enunciativa (Guirado, 1995 : 23). 
Para Foucault el discurso es una violencia hecha sobre las cosas " $[\ldots]$ una práctica que les imponemos; es en esta práctica donde los acontecimientos del discurso encuentran el principio de su regularidad" (Foucault, 1999: 44).

Según Foucault (1996), los elementos que componen el discurso están dados por los objetos que son referenciados, por los tipos de enunciados, por los conceptos utilizados y por los temas y teorías que dominan su sistema interno de relaciones y la formación discursiva en la cual se integra. También es importante comprender cómo operan los mecanismos de supresión de otros discursos. El sujeto, en la lectura focaultiana "[...] es un espacio a ser ocupado por diferentes individuos que lo ocuparan al formular el enunciado " (Nagamine-Brandáo, $1996: 30)$.

La definición foucaultiana de discurso podría, en una lectura superficial, vincularse al construccionismo social, que intenta relacionarse con Foucault a partir de la afirmación de que la realidad está contenida en el discurso, en la primacía ontológica del mismo.

El análisis de discurso trabaja sobre una cierta primacía del lenguaje, pero lo coloca en una relación diferente respecto de sus determinaciones, definiendo un vínculo dialéctico de la realidad social con aquélla, donde lo social es ontológicamente anterior. El discurso, para el análisis de discurso, tiene un carácter procesual que lo vincula con lo económico, lo histórico y lo cultural, por ejemplo, y por tanto, con la expresión (parcial) de una realidad compleja.

El signo, en el análisis de discurso, es producto de un consenso entre individuos socialmente organizados en el decurso de un proceso de interacción, estando condicionado "[...] tanto por la organización social de los individuos como por las condiciones dentro de las cuales esa relación acontece" (Bakthin, 1929/1999: 30; Bravo, 2000 : 71).

De esta manera, se toma distancia de una concepción idealista del sujeto, "[...] un sujeto libre, que exprimiría un sentido preexistente reflejándolo mecánicamente por medio del lenguaje" (Serrani, 1993 : 23).

\section{Análisis discursivo de los pericias realizadas a los internos de la ATP}

A continuación, se hace un análisis de tres conjuntos de pericias pertenecientes a tres internos del Ala de Tratamiento Psiquiátrico del Distrito Federal y una comparación posterior con los discursos presentes en los laudos psiquiátricos realizados en el Manicomio Judicial H. Carrillo entre los años 1939 y 1959. 


\section{Primitivo y peligroso}

"A", de 31 años de edad, fue preso acusado de violar a un menor de seis años en Paranoá, ciudad donde reside desde que llegó con su familia proveniente de un Estado de la región nordeste. La víctima era un vecino del acusado. Luego de cometido el delito, huyó; una vez detenido negó haber sido el responsable.

"A" no tenía familia constituida en la época del crimen. Su esposa lo había abandonado porque "[...]lo creía loco". Sin haber completado el ciclo primario, trabajaba ocasionalmente como jardinero. Según consta en el proceso el acusado era consumidor habitual de alcohol, como su padre. No registraba antecedentes psiquiátricos, a pesar de que la madre relató conductas extrańas desde la adolescencia.

El primer laudo se realizó en el año 1998, época de su ingreso al Ala Psiquiátrica. El diagnóstico inicial fue de oligofrenia, a pesar de que en el mismo análisis se considera la posibilidad de que sea fronterizo o borderline, diagnósticos incompatibles con el anterior. Este examen consideró al acusado "primitivo y peligroso".

La pericia del año 1999, reitera el carácter peligroso del periciado, destacando que esa condición tiene que ver con su comportamiento primitivo. Se destaca que el sujeto presenta problemas para dormir, precisando de medicación.

El laudo del año 2000 diagnostica un retardo mental leve, sin que el estado mental del sujeto haya manifestado progreso.

El último de los laudos analizados fue realizado en el año 2001 y no incluye un diagnóstico definido, apenas insiste en la asociación entre la impulsividad derivada del comportamiento primitivo y su carácter peligroso.

Estos laudos insisten en asociar la supuesta peligrosidad del sujeto a su carácter primitivo. Esta asociación se impone a la ya establecida entre el diagnóstico de oligofrenia o debilidad mental y peligrosidad.

Esta caracterización de primitivo y peligroso supone un momento ontológico del desarrollo social y humano, supuestamente ya superado por la sociedad actual. Un sujeto con una patología psiquiátrica derivada de causas físicas, como sería la oligofrenia o la debilidad mental, integraría este estadio pre-social que determina su conducta criminal, en este caso, la violación a un niño.

Dos de los laudos indican la falta de progreso del estado mental del sujeto pero sin preocupación alguna por indagar sobre sus condiciones institucionales ni sobre el tipo de tratamiento que recibe o debería recibir, como si estas cuestiones no tuvieran relación.

Por otra parte, el tipo de tratamiento institucional recibido por " $\mathrm{A}$ ", basado apenas en su reclusión, impide cualquier elaboración posterior del hecho que 
lo llevó a esa situación, mucho menos elaborar la culpa y asumir la responsabilidad del mismo, proceso indispensable para evitar la reincidencia penal y parte necesaria de un proceso terapéutico.

La historia de vida de "A", transformada por el proceso y los laudos apenas en la historia de un crimen y una patología, muestra un grado importante de exclusión social y dificultades de acceso material y simbólico a una atención en salud mental y de salud en general.

Considerando que los diagnósticos se refieren a patologías de base somática, "A" debería según la lógica de estos textos, permanecer en la ATP indefinidamente, dada la asociación entre su dolencia (incurable) y su peligrosidad.

Existen aquí tres operadores discursivos e institucionales principales: peligrosidad, primitivismo y los diagnósticos de base física. Entre los tres, los dos primeros tienen más peso, teniendo los últimos un carácter casi accesorio, complementarios de esa asociación inicial.

\section{El drogado peligroso}

"C", de 41 años de edad, nativo de la ciudad de Ceilandia, ingresó en el Ala de Tratamiento Psiquiátrico en el año 1993. Originalmente fue detenido por porte de drogas, incluyéndose después una acusación por intento de homicidio. "C", vivía en la época con su hermana, tenía estudios primarios incompletos y no presentaba antecedentes laborales. Es separado de su esposa con la cual tiene dos hijos. En el proceso se destaca que era, en el momento del crimen, un consumidor habitual de drogas, principalmente de "merla" (derivado de la cocaína), registrando también antecedentes psiquiátricos.

El primer laudo, realizado en el año de ingreso del periciado al ala psiquiátrica, lo considera esquizofrénico paranoide y peligroso, a pesar de aclarar que estaba psíquicamente bien orientado al momento del examen. El mismo texto indica la presencia de ideas delirantes en el sujeto, que habrían comenzado con el consumo de drogas. Cabe destacar aquí que en el Distrito Federal se registra un alto consumo de merla, producto éste de efectos rápidos y devastadores y entre cuyos síntomas aparecen con frecuencia manifestaciones delirantes y persecutorias (denominadas "noia" por los propios usuarios).

El laudo siguiente, hecho en el año 1998, diagnostica a "C" como portador de una psicosis procesual, asociada a su peligrosidad. El mismo texto considera el cuadro psicótico anterior como transitorio e inducido por el uso de alcohol y drogas. 
El laudo del año 1999 considera que el periciado estaba bien orientado, manteniendo capacidad de juicio crítico para con sus actos, siendo nuevamente considerado no peligroso.

En el año 1999 fue autorizado a visitar a su madre enferma. Posteriormente, ya en tratamiento ambulatorio, "peleaba mucho" según el laudo y no compareció ante la justicia en la fecha prevista. Por ese motivo, vuelve al Ala de Tratamiento Psiquiátrico en el año 2000.

El último laudo, hecho en el año 2002, se vuelve al diagnóstico inicial de esquizofrenia insistiendo en la cesación de peligrosidad del sujeto.

En el caso de "C" llaman la atención los sucesivos diagnósticos de cesación de peligrosidad, que no parecen influir en su condición institucional. Hay también una cierta insistencia en relacionar los diferentes diagnósticos con la condición de usuario de drogas del sujeto En este caso, esta asociación entre una patología psiquiátrica (cualquier) y el uso de drogas parece determinar su condición inicial de peligroso. Una vez en reclusión, la condición de peligroso desaparece, probablemente por la suposición de que el consumo de drogas había cesado.

A pesar de que la relación entre los crímenes cometidos, principalmente aquél que involucraba agresión interpersonal, y los cuadros patológicos definidos podrían determinar una condición de peligrosidad más estable y duradera, como acontece en los otros casos y siempre considerando la lógica que guía estos discursos, la cuestión del consumo de drogas parece ser aquí el determinante principal para esta caracterización temporal de peligrosidad.

El diagnóstico de dependencia de drogas es el responsable de muchos de los ingresos de sujetos infractores a los manicomios judiciales en los últimos años. Este tipo de enunciado parece "[...] precipitar un saber y causar una prisa por concluir" (Le Poulichet, 1990: 17) siendo el toxicómano "[...] efecto de una elaboración secundaria fundada en una tentativa retratística." (Le Poulichet, 1990: 27).

Stevenson en su obra O médico e o monstro: Dr. Jekill e Mr. Hide (1996) relata la historia de un científico creador de una droga capaz de transformar a un sujeto honesto en un peligroso criminal. Una vez cesado el efecto, la persona retornaba a su estado normal de inmediato.

Este es el presupuesto que parece guiar esta serie de diagnósticos y con frecuencia, la clínica de la toxicomanía (principalmente aquella basada en la abstinencia como único propósito), que centra el abordaje solamente en la cuestión del objeto o, peor, apunta a reintegrar al usuario a determinados circuitos familiares o sociales con un objetivo más disciplinario que clínico. De una u otra forma se 
ignoran o relegan otras cuestiones clínicas, como la discriminación entre usuario y dependiente posibles manifestaciones de co-mórbidas asociadas a ese consumo.

Una vez más en el caso de C, la solución institucional es la reclusión del sujeto, sin preocupación alguna por tratamiento o acompañamiento clínico.

\section{Extremadamente peligroso}

"E" de 31 años de edad, nació en la ciudad de Gama, siendo el cuarto hijo entre siete. No consiguió completar el ciclo primario y nunca trabajó en empleos estables.

En el año 1991 le disparó a una persona en una fiesta, huyendo posteriormente. En el año 1993, robó una caja de cerveza a una persona junto con unos amigos. Un allegado al asaltado, que había salido en la búsqueda de los ladrones, fue agredido brutalmente por " $\mathrm{E}$ ” y su grupo: primero lo golpearon, después lo lanzaron al piso, lo apedrearon y le dispararan, matándolo. En el juicio, intentó justificar su inocencia con un lenguaje bien articulado, según consta en el proceso.

"E" fue condenado a 18 años y seis meses de prisión. En la prisión sufrió varias sanciones disciplinarias por posesión de un arma blanca y agredir a otro detenido con la misma. Por ese motivo, fue trasladado al ala denominada "segura”, reservada a los presos que sufren amenazas de muerte de sus compañeros. También en esa época comenzó a manifestar problemas mentales, siendo tratado tres veces en el servicio de Emergencia del Hospital de Taguatinga.

Finalmente, en el año 1999, es considerado inimputable y transferido al Ala de Tratamiento Psiquiátrico.

El primer laudo hecho en 1999 encuentra a "E" en malas condiciones de higiene, delirante y predicando la Biblia. Según el relato de una funcionaria de la Vara de Ejecuciones Criminales (organismo responsable legal de estos procesos) que complementa este examen, "E" lanzaba la comida a la basura y la buscaba nuevamente.

El laudo hecho en el año 2000 cita antecedentes de epilepsia en el periciado y refiere a la falta de delirios o alucinaciones, destacando su fluidez verbal. Describe su patología como una epilepsia con episodios psicóticos, en fase de intercrisis. "E" es considerado en este momento extremadamente peligroso y con pocas oportunidades de curación. En el mismo año, la opinión de una asistente social lo encuentra apto para encaminarlo a la Clínica psiquiátrica de Planalto. En este último laudo consta también la gran cantidad de medicación psiquiátrica que "E" estaba tomando.

Esta fue una de las personas contactadas por el equipo en las esporádicas visitas realizadas a la institución. Su aspecto distaba mucho de ser aquél descrito 
en los informes: en la época de este contacto, "E" se encontraba en estado casi catatónico, sin poder articular un habla coherente o prolongada y siendo víctima de burlas y agresiones por parte de otros internos. La participación en los hechos que lo llevaron a prisión, así como su discurso de defensa bien articulado en el juicio, parecen haber pertenecido a otra persona. Aún así, lo que restó física y psíquicamente de "E" después de algunos ańos en la institución y de la brutal medicación aplicada, todavía es considerado extremadamente peligroso por el examen pericial, que una vez más parece centrarse en el crimen cometido y no en la persona.

Nuevamente, esta supuesta peligrosidad extrema no mantiene relación con los cuadros diagnósticos presentes en los laudos, que por su vez distan de ser coherentes con la trayectoria de deterioro psíquico de "E", poco asimilable a una epilepsia.

En la novela La Metamorfosis, Kafka (1898/1961) describe la historia de Gregor Samsa, que amaneció un día transformado en insecto, lo que lo llevó a su progresiva desaparición social y familiar y finalmente a su muerte, considerada un alivio para todos. "E", que en libertad era apellidado de Cucaracha, parece encaminado a cumplir también el triste destino de la figura del relato kafkiano, estando su destino limitado al Ala Psiquiátrica o a un asilo, formas ambas de muerte social.

\section{Análisis discursivo de los laudos del Manicomio Judicial H. Carrilho}

En 1929, la población del Manicomio Judicial Heitor Carrilho de Río de Janeiro estaba constituida por 21,4\% de esquizofrénicos; $21,4 \%$ de psicóticos alcohólicos; $18,2 \%$ de oligofrénicos; $8,2 \%$ de paralíticos en general; $5 \%$ de sifilíticos cerebrales y $6 \%$ de otros tipos de psicóticos, siendo que el $8 \%$ no eran considerados alienados. De este total, $22 \%$ de los sujetos fueron procesados por vagabundos (Carrilho, 1930). En esta primera época, el Manicomio Judicial era descripto como el lugar de reclusión de los terribles, de los incorregibles, de los amorales constitucionales, destinado a ofrecer a esa población la "[...] ortopedia moral de la que carecen" (Carrilho, 1931: 30).

De uno de estos sujetos, un perito opinaba que "[...] su fisonomía refleja de algún modo su simplicidad mental que recuerda, hasta cierto punto, a los individuos del campo" (Carrilho, 1930: 107). Esta consideración por el origen social del periciado aparece también en otros laudos del mismo año, en la preocupación de uno de los peritos por el efecto que un libro como la Biblia puede causar "[...] en individuos incultos carentes de sentido crítico" (Carrilho, 1930 : 153). 
La peligrosidad de esta población (definida también en una época como temibilidad) está relacionada con una inclinación natural al mal, que en los casos de alcoholismo constituía “...un peligro individual y social” (Carrilho, 1931: 35).

Los exámenes de aquella época dan especial atención a los signos somáticos de degeneración, como la distribución irregular del vello corporal y los dientes o la forma de los pabellones auriculares.

En un laudo del año 1934, el perito destaca la ineficacia de las penas aplicadas a aquel tipo de sujeto que "[...] vive en constante repugnancia al esfuerzo" (Carrilho, 1934: 23), merecedor por esto de medidas de seguridad. En uno de los sujetos sometidos a peritaje, diagnosticado como portador de hemiplejía orgánica, se destaca el hecho de que "[...] pasó a frecuentar mujeres de vida dudosa..." adquiriendo "... el hábito de entrar en casas de bebida" (Carrilho, 1934: 54).

En el año 1937, el doctor Bourgoy de Mendonça coloca como propósito de la psiquiatría la profilaxia de la criminalidad, y la necesidad de actuar contra los "...bandidos de origen étnico, económico-social y patológico" (Bourgoy de Mendonça, 1937 : 15). Por eso, Nobre de Mello considera necesario que el "[...] delincuente sea encarcelado, no por lo que ha hecho, sino por lo que es" (Nobre de Mello, 1937 : 30).

En algunos exámenes se afirma la relación entre sífilis y tuberculosis como fuentes de perturbaciones psíquicas y de conductas antisociales.

Algunos relatos sobre los hechos que llevaron a los sujetos a involucrarse con la justicia llaman la atención. En el año 1939, una persona recurrió a la delegación policial para denunciar su creencia de ser perseguida, y en una discusión posterior con los policías acabó siendo herida por un disparo. El examen consideró a este sujeto como inimputable, no dejando claro cuál fue el crimen cometido.

En el mismo año, en uno de los textos se destacan en el campo jurídico, "[...] las reformas provocadas por la revolución fascista en Italia" (Carrilho, 1939 : 99).

Dos años después, un artículo que intenta profundizar la cuestión de la responsabilidad criminal de los sujetos se preocupa por " [...] recordar que un indio bárbaro puede ser inteligente” (Carrilho, 1941 : 86). Otros sujetos de peritaje no merecen tantas consideraciones, ya que el examen verifica que "[...] su hábitat natural es la escoria y sus compañeros son todos maleantes y alborotadores" (Carrilho, 1941: 161). Probablemente estas personas eran referenciadas como indican Pinel, Esquirol, Krafft-Ebing, como las que "[...] tienen encarnado el espíritu de la mentira y de la astucia” (Duarte, 1940: 96).

Intentando la etiología de estas alteraciones morales se realizó, años más tarde, una consideración sobre la tuberculosis y la conducta delictiva, llegando a la conclusión de que el delincuente tuberculoso puede transformarse en un 
"...oportunista con el sentido moral afectado", siendo que esta enfermedad "... da una cierta perversidad al individuo", observando también que en ellos "... el sentido religioso decae o disminuye" (Arruda, 1959: 27).

Otras causas externas podrían concurrir para generar este tipo de conducta y personalidad, como, por ejemplo, el uso de marihuana, considerada una"... planta asesina que libera la agresividad natural del hombre" (Arruda, 1959: 62).

\section{Consideraciones finales}

A partir del análisis de los laudos de los internos del Ala de Tratamiento Psiquiátrico de Brasilia seleccionados y su relación con otros informes y discursos anteriores, como los del Manicomio Judicial Heitor Carrilho, es posible afirmar que el discurso psiquiátrico prevalece sobre el jurídico desde el momento en que la justicia cede su lugar a la psiquiatría en la determinación de responsabilidad penal e imputabilidad de los sujetos. No obstante, el discurso de la psiquiatría no mantiene una lógica clínica basada en el diagnóstico y el pronóstico clínico, sino que asume un lugar jurídico de juicio y sanción.

El operador discursivo que permite a la psiquiatría ocupar este espacio es el de la peligrosidad. Este concepto de peligrosidad es utilizado de forma maleable, sujeto a otras consideraciones secundarias, como las de forma, grado y motivos del crimen, que acrecientan o perpetúan esa condición.

La sanción de peligrosidad en todas sus formas está vinculada, en primer lugar, a la relación establecida entre el tipo de crimen cometido y la supuesta condición de enfermo mental del infractor, teniendo las otras cuestiones un carácter secundario. El diagnóstico, como ya se vio en el análisis de los casos, no mantiene una lógica clínica de asociación con el hecho cometido y otras características personales de los sujetos analizados, operando apenas como justificador de esa sanción de peligrosidad.

Debido al carácter secundario que ocupan en la trama discursiva de los laudos, los diagnósticos pueden cambiar de un examen a otro y ser contradictorios entre sí. Su propósito no es clínico sino jurídico: el de permitir sancionar la locura y el malestar psíquico cuando asociados a una infracción a la ley.

Una vez establecida la relación entre crimen y enfermedad mental, el diagnóstico es el instrumento que habilita al psiquiatra para ocupar ese lugar de juez.

Así, si el derecho penal en su versión más progresista apunta al castigo del infractor por lo que hizo y no por lo que es, el discurso psiquiátrico, en el espacio particular de las medidas de seguridad, castiga una personalidad y no una acción.

La supuesta asepsia de los discursos jurídicos-diagnósticos presentes en los laudos les permite tomar distancia de las consecuencias institucionales y 
subjetivas de su aplicación. De esta forma, la cronificación de muchos de los sujetos objeto de estas prácticas y discursos, consecuencia directa de la falta de tratamiento adecuado y de las pésimas condiciones institucionales en general, es considerada en los laudos como derivada exclusivamente de su condición patológica. Ocurre aquí una contradicción: cuando se verifica el deterioro de las condiciones físicas y mentales de los sujetos examinados, los diagnósticos de peligrosidad son ratificados; cuando, como consecuencia de las sucesivas sanciones los mismos se cronifican y llegan a un estado de deterioro absoluto, se considera el fin de la peligrosidad. Así el discurso psiquiátrico actúa en dirección contraria al supuesto propósito de las medidas de seguridad, que es la de curar y reinsertar socialmente a esta población.

El contenido ideológico del discurso psiquiátrico-legal aparece de forma más evidente en las consideraciones presentes en muchos de los laudos sobre la relación entre el origen social de los sujetos, su nivel de inteligencia, su disposición para el trabajo y/o el estudio y el mantenimiento del diagnóstico de peligrosidad. Aparecen aquí trazos discursivos del discurso fundacional de la psiquiatría y del derecho penal de comienzos de la época moderna, dirigidos ambos a contener y disciplinar al subproletariado y ajustarlo para integrarse a las relaciones sociales de producción que el capitalismo demandaba.

Estos contenidos ideológicos se manifiestan también en los laudos y discursos producidos en el Manicomio Judicial Heitor Carrilho. Los presupuestos teóricos y epistemológicos de la época, principalmente los de la degeneración y el atavismo y, en algún momento, ciertas condiciones políticas, permitieron que la asociación entre clase social y peligrosidad pudiera ser establecida de forma más directa y abierta, incluyendo aún elogios ocasionales a los modelos penales y sociales de los regímenes fascistas europeos.

A partir de esta referencia histórica, es posible ver como el carácter secundario del diagnóstico aparecía también en la estructura discursiva de esos laudos. Partiendo de otras bases teóricas y clínicas distintas a las utilizadas entre los internos del Ala de Tratamiento Psiquiátrico, se llegó a las mismas conclusiones. Así, un sujeto considerado peligroso en los laudos del Manicomio Judicial Heitor Carrilho por su condición primitiva o por ser portador de tuberculosis, tendrá también esa condición en los laudos del Ala de Tratamiento Psiquiátrico asociada en este caso a esquizofrenia o sociopatía, por ejemplo.

El carácter jurídico de los discursos psiquiátricos presente en los laudos aquí considerados aparece de forma más evidente en los casos en que éstas manifiestan su funcionalidad con las formas burocrático-legales de las medidas de seguridad. La sanción de continuidad de la peligrosidad justificada por la falta 
de familia o condiciones económicas que permitan la reinserción social de los sujetos, denuncia ese carácter.

El discurso psiquiátrico presente en los laudos analizados integra una formación discursiva de carácter jurídico que se propone sancionar a los infractores de la ley, considerados penalmente como inimputables y portadores de enfermedad mental, con la reclusión y la medicación forzada. Estas sanciones se destinan a castigar un tipo particular de personalidad y se aplican a determinados sectores sociales caracterizados por su vulnerabilidad social y subjetiva: pobres, inmigrantes, psíquicamente frágiles y sin redes sociales de contención ni acceso a servicios de salud. Esa vulnerabilidad aumenta cuando estos sectores son expuestos a la acción de la justicia penal, ya que la gran mayoría no tiene acceso a los mecanismos de defensa legales de los cuales disponen otras clases y sectores.

Compartiendo este espacio difuso y nunca bien delimitado, los discursos de la psiquiatría y de la justicia penal no asumen las consecuencias de esta práctica común, lo que ha permitido que históricamente "[...] magistrados y médicos pudieran mirarse ante el espejo sin sentir miedo" (Foucault, $1982: 200$ ).

\section{Bibliografía}

Aquino, Ana Paula (2008), Da Lei às leis: reflexóes teórico-clínicas sobre os inimputáveis. Dissertação de Mestrado em Psicologia Clínica. Universidade de Brasília, D.F.

Arruda, Elso (1959), "O delinqüente tuberculoso", en: Arquivos Manicômio Judiciário, No. 19, Vol. 2, pp. 27-58.

Bakthin, Mikhail (1999), Marxismo e filosofia da linguagem. Hucitec, São Paulo. (Versión original 1929).

Beccaria, Cesare (2000), De los delitos y las penas. Temis, Bogotá. (Versión Original 1756).

Bourgoy de Mendonça, Mario (1937), "Aspectos médico-legais e sociais do problema da Vadiagem", en: Arquivos Manicômio Judiciário, No. 17, Vol. 1, pp. 13-18.

Código Penal (2002), Saraiva, São Paulo. 
Bravo, Omar (2000), Discurso sobre drogas nas instituiçóes do Distrito Federal. Dissertação de Mestrado em Psicologia Clínica. Universidade de Brasília, D.F.

Carrilho, Heitor (1930), "Delinqüentes internados no Manicômio Judiciário Heitor Carrilho”, en: Arquivos Manicômio Judiciário, No. 1, Vol. 1, pp. 47-67.

Carrilho, Heitor (1931), "Anthropologia Penitenciaria”, en: Arquivos Manicômio Judiciário, No. 2, Vol. 2, pp. 11-20.

Carrilho, Heitor (1934), "Em torno das formas mentais prolongadas da encephalite epidémica”, en: Arquivos Manicômio Judiciário, No. 4, Vol. 1, pp. 5-26.

Carrilho, Heitor (1939), Laudos e Documentos Psiquiátrico-Legais. Arquivos Manicômio Judiciário Heitor Carrilho, No 2, Vol 2, pp. 63-87.

Carrilho, Heitor (1941), "A responsabilidade criminal no novo Código Penal", en: Arquivos Manicômio Judiciário, No. 11, Vol. 3, pp. 78-139.

Cohen, Claudio (Org.) (1996), Saúde mental, crime e justiça. EDUSP, São Paulo.

Duarte, José (1940), "Responsabilidade criminal" Arquivos Manicômio Judiciário, No. 10, Vol. 2, pp. $94-102$.

Foucault, Michel (1973), El orden del discurso. Tusquets, Barcelona.

Foucault, Michel (1982), Eu, Pierre Riviere, que degolei minha mäe, minha irmã e meuirmão. Graal, Rio de Janeiro.

Foucault, Michel (1991), Vigiar e punir. Vozes, Petrópolis.

Foucault, Michel (1996), La vida de los hombres infames. Editorial Altamira, La Plata.

Foucault, Michel (1999), A verdade e as formas juridicas. PUC, Rio de Janeiro. Foucault, Michel (2001), Os anormais. Martins Fontes, São Paulo.

Guirado, Marlene (1995), Psicanálise e Análise de Discurso. São Paulo: Summus. 
Kafka, Franz (1961), O processo. Nova Esperança, São Paulo. (Versión original 1898).

Le Poulichet, Silvie (1990), Toxicomania y Psicoanálisis. Amorrortu Editores, Buenos Aires.

Nagamine Brandão, Helena (1996), Introdução a Análise de Discurso. Unicamp, Campinas.

Nobre de Mello, Sergio (1937), Personalidade esquizotímica com desvios éticos constitucionais. Arquivos Manicômio Judiciário, No 2, Vol 1, pp. 29-33.

Serrani, Silvana (1993), A linguagem na pesquisa sociocultural. Unicamp, Campinas.

Stevenson, Robert (1966), O médico e o monstro: Dr. Jekill e Mr. Hide. L \& M Editores, Porto Alegre. (Versión original 1881).

Zaffaroni, Eugenio e Pierangeli, José (1999), Manual de direito penal Brasileiro. Ed. Revista dos Tribunais, São Paulo. 
